\title{
Cox Regression of Factors Associated with the Onset of Chronic Kidney Disease in HIV/AIDS Patients in Albert Luthuli Municipality of South Africa
}

\author{
Pepukai Bengura ${ }^{1, *}$, Principal Ndlovu², and Mulalo Annah Managa² \\ ${ }^{1}$ Department of Statistics, Department of Psychology, University of South Africa, South Africa \\ ${ }^{2}$ Department of Statistics, University of South Africa, South Africa
}

*Corresponding author: Pepukai Bengura, Department of Statistics, Department of Psychology, University of South Africa, South Africa, Phone: +27834535013; E-mail: 31659322@mylife.unisa.ac.za

Received: 28 May, 2021 | Accepted: 10 Jun, 2021 | Published: 23 Jun, 2021

Citation: Bengura P, Ndlovu P, Managa MA (2021) Cox Regression of Factors Associated with the Onset of Chronic Kidney Disease in HIV/AIDS Patients in Albert Luthuli Municipality of South Africa. Int J Nephrol Kidney Fail 7(2): dx.doi.org/10.16966/2380-5498.212

Copyright: (C) 2021 Bengura P, et al. This is an open-access article distributed under the terms of the Creative Commons Attribution License, which permits unrestricted use, distribution, and reproduction in any medium, provided the original author and source are credited.

\begin{abstract}
Background: Current research indicates that chronic kidney disease is a global problem that poses a major health threat to people of poor countries with HIV/AIDS and on antiretroviral treatment. The kidney disease tends to be aggravated by the setting in of COVID-19. In this study, the prevalence of chronic kidney disease and the factors associated with it were investigated among the HIV/AIDS patients in a rural community of South Africa.
\end{abstract}

Methods: A cohort of HIV/AIDS patients were retrospectively followed from 2010 to 2017 until chronic kidney disease was diagnosed or until the end of the observation period at two hospitals (Carolina and Embhuleni). Patient information was obtained from the routine hospitals' records, and the data were analysed using Cox regression and survival analysis (Kaplan-Meier hazard functions and ratios, and log-rank tests) methods.

Results: Out of a random sample of 320 HIV/AIDS patients, 51 patients (15.9\%) had chronic kidney disease. The factors associated with chronic kidney disease were: gender ( $p$-value $=0.0356)$, age ( $p$-value $=0.00077)$, baseline creatinine ( $p$-value $=0.00253)$, follow-up alanine transaminase ( $p$-value $=0.0152)$, ART treatments ( $p$-value $<0.00193$ ) and hospital ( $p$-value $=0.00258)$.

Discussion: Whilst antiretroviral treatment is associated with some improvement in virology and immunology in HIV-infected patients, research is still needed for the assessment of the impact of ART and other risk factors on renal function in marginalised communities in Africa. The expected action to alleviate the health threat due to CKD in South Africa is to educate the nation on prevention, early detection and the management of the disease.

Keywords: HIV/AIDS; Renal disease; Glomerular filtration rate; ART; Prevalence; Risk factors; Cox regression; Kaplan-Meier Estimator; Hazard ratio

\section{Background}

HIV/AIDS has been a major health problem worldwide for more than three decades now. According to the WHO global statistics: since the beginning of the epidemic, 75 million people have been infected with the HIV, about 32 million people have died of HIV and globally, 37.9 million people were living with HIV at the end of 2018 [1]. According to United Nations Agency for International Development (UNAIDS) AIDS info [2], South Africa has the biggest and most high-profile HIV epidemic in the world, with an estimated 7.7 million living with HIV in 2018. South Africa's Mpumalanga province has the second-highest HIV prevalence rate after KwaZulu-Natal province. Gert Sibande district which is in Mpumalanga province is leading all districts in the country with a $46.1 \%$ HIV prevalence rate [3]. Gert Sibande district has Albert Luthuli as one of its municipalities whose HIV prevalence stood at $43.2 \%$ [4].

Human Immunodeficiency Virus (HIV) affects every organ system in the body by direct damage or by rendering the host susceptible to opportunistic infections [5]. The commonest sites of infection include kidneys. CKD poses a major health threat to people living in poor countries, especially when it is combined with HIV, antiretroviral treatment (ART), or communicable and non-communicable diseases [6].

According to Labuschagne I, et al., [7], CKD is a global problem with about $10 \%$ of the world's population suffering from the disease. Ekrikpo UE, et al., [8] in agreement with Eneyew K, et al., [9] and Crum-Cianflone $\mathrm{N}$, et al., [10] pointed out that the prevalence of renal dysfunction is projected to increase as the life expectancy of the HIVinfected individual's increases due to drug therapy. This study which focuses on the rural population was motivated by among other factors by the fact that $93 \%$ of the studies on CKD in sub-Saharan Africa were done in urban settings [11].

The objective of this study was to use the Cox regression method to determine the prevalence of $\mathrm{CKD}$ and to identify the factors associated with CKD among HIV/AIDS patients on ART by using data from Albert Luthuli municipality hospitals in South Africa. 


\section{Methods}

\section{Study design and setting}

A cohort of HIV + terminally ill patients was retrospectively followed from 2010 to 2017 until CKD was diagnosed or until the end of the observation period at the two hospitals (Carolina and Embhuleni) in Albert Luthuli Local Municipality. This is a South African municipality situated in the Gert Sibande District of Mpumalanga Province. Carolina and Embhuleni district hospitals offer comprehensive health care services which include HIV/AIDS and tuberculosis (TB) treatments to the surrounding communities in Albert Luthuli municipality. These hospitals are accredited antiretroviral (ARV) treatment initiation and ongoing treatment sites. Both Hospitals serve mostly the rural population in Albert Luthuli Municipality. The target population which was used as a sampling frame included all HIV/ AIDS patients ( $\geq 16$ years) admitted and started ART treatment in the two hospitals within the three months from the $1^{\text {st }}$ of January to the $31^{\text {st }}$ of March 2010. The variables which form part of the routine hospital records in Albert Luthuli municipality were used in this study and are described as follows. CKD status is the dependent variable for the study. It was recorded in terms of CKD status (yes, no) and time until its onset. The categorical independent variables were gender, hospital (Carolina, Embhuleni), WHO stage (1, 2, 3, 4), marital status (single, married, staying together, widowed/separated/divorced), treatments (regimen1) $\quad(\mathrm{NVP}+\mathrm{D} 4 \mathrm{~T}+3 \mathrm{TC}, \quad \mathrm{EFV}+\mathrm{D} 4 \mathrm{~T}+3 \mathrm{TC}, \quad \mathrm{EFV}+\mathrm{AZT}+3 \mathrm{TC}$ and EFV+3TC+TDF), ART adherence (poor, fair, good), transferred from the hospital (yes, no) and lost to follow-up (yes, no). The continuous independent variables for the study which except age were classified into baseline and follow-up variables were mass, CD4 cell count, haemoglobin, lymphocyte, white blood cell count, viral load, creatinine, total protein, sodium and alanine transaminase. Diabetes and hypertension were excluded because their records were found in very few patient files. HIV/AIDS patients with missing essential records such as baseline creatinine, gender and date of birth or age were excluded from the study.

\section{Sample size and sampling procedure}

The sample size was determined by using sample size calculation formula for survival analysis by considering the following statistical assumptions on HIV-infected patients: an average of $13 \%$ prevalence rate of renal insufficiency among ART naïve patients [12], 5\% precision or margin error, $95 \%$ level of the confidence interval and 0.45 loss [13]. The sample size was calculated using the formula [9], $N=\frac{Z^{2} p(1-p)}{\alpha^{2}}$ where $\mathrm{N}=$ sample size, $\mathrm{Z}=1.96$ (critical value at $95 \%$ level of confidence), $\mathrm{p}=$ proportion of renal insufficiency and $\alpha=$ type- 1 error (0.05) was 320 . The estimated total sample size was proportionally and randomly allocated to the two study sites (Embhuleni and Carolina hospitals with proportions of $78 \%$ and $22 \%$ respectively) and according to the age and gender proportions (39.4\% male) as per population proportions.

\section{Ethical considerations}

The ethical approval for this study was granted by UNISA Ethics Review Committee with the approval number being 2017/SSR ERC/005. The permission to conduct the study at Carolina and Embhuleni hospitals was obtained from Mpumalanga Department of Health with the permission number being MP_201708_013. All data relating to the patients were handled with the utmost confidentiality in all the stages of the research. In addition, no reference to an individual respondent was made as all results were handled in aggregate format. The electronic documents carrying confidential information on patients are all protected by some encryption and will be destroyed as per research policy.

\section{Clinical determination of CKD status}

The patient's CKD status was determined by referring to the South African National Health Laboratory Service report on Chemical pathology. CKD status was determined from the estimates of the Glomeruli Filtration Rate (GFR) using Modification of Diet in Renal Disease $(\mathrm{MDRD})$ formula GFR $\left(\mathrm{ml} / \mathrm{min} / 1.73 \mathrm{~m}^{2}\right)=175 \times\{$ [plasma creatinine $(\mu \mathrm{mol} / \mathrm{l}) / 88.4]-1.154\} \times$ age (years)-0.203 $\times 0.742$ (if female) $\times 1.212$ (if African American) $[14,15]$. The renal impairment in this study was classified according to the National Kidney Foundation clinical practice guideline with estimated GFR values $\geq$ $90 \mathrm{ml} / \mathrm{min} / 1.73 \mathrm{~m}^{2}, 60-89 \mathrm{ml} / \mathrm{min} / 1.73 \mathrm{~m}^{2}, 30-59 \mathrm{ml} / \mathrm{min} / 1.73 \mathrm{~m}^{2}, 15-$ $29 \mathrm{ml} / \mathrm{min} / 1.73 \mathrm{~m}^{2}$ and $<15 \mathrm{ml} / \mathrm{min} / 1.73 \mathrm{~m}^{2}$ interpreted as normal, mild, moderate, severe and kidney failure respectively. As in Iseki [14], patients were categorized as having CKD if their GFR was less than $60 \mathrm{ml} / \mathrm{min} / 1.73 \mathrm{~m}^{2}$ for more than 3 months. The time duration until the onset of CKD was calculated using the formula: Time duration until CKD onset $=\left(\right.$ Date on which eGFR below $60 \mathrm{ml} / \mathrm{min} / 1.73 \mathrm{~m}^{2}$ was confirmed-Date of ART initiation). This equation was programmed in the data collection Research tool [15].

\section{Statistical methods}

Let $\boldsymbol{X}_{i}^{T}=\left(X_{i 1}, X_{i 2}, \ldots, X_{i p}\right)$ be a $\mathrm{p}$-dimensional vector of the values of the covariates associated with the $\mathrm{i}^{\text {th }}$ patient. Then, the Cox proportional hazards regression model is $[16,17]$,

$$
h_{i}(t)=h_{0}(t) \exp \left\{\boldsymbol{X}_{i}^{T} \boldsymbol{\beta}=\sum_{j=1}^{p} \beta_{j} X_{i j}\right\}(1)
$$

where $\boldsymbol{\beta}^{T}=\left(\beta_{1}, \beta_{2}, \ldots, \beta_{p}\right)$ is a $\mathrm{p}$-dimensional vector of regression coefficients to be estimated from the data, and $h_{0}(t)$ is the unspecified baseline hazard function that does not have to be estimated. The hazard model in the model (1) makes no assumptions about the shape of the hazard function over time. A hazard function could be constant, increasing, decreasing, or it could be a combination of two or three of these graph trends.

Model (1) can be written in terms of the survivor function [18],

$$
S_{i}(t)=S_{0}(t)^{\exp \left\{\boldsymbol{X}_{i}^{T} \boldsymbol{\beta}\right\}(2)}
$$

the assumptions of the model (1) which may be violated by the data are: (i) the covariates $\boldsymbol{X}_{i}^{T}$ do not vary with time and hence the hazard rate ratios of pairs of patients do not vary with time; (ii) censoring and survival are independent, and (iii) the log hazard rate is indeed a linear function of the covariates. Model (1) was fitted to the data using coxph function in R Version 3.5.1 to determine the risk factors associated with CKD. Firstly, the variables in table 1 were tested one by one and variables with $\mathrm{p}$-values $<0.25$ were considered in the final Cox regression analysis. The final multivariate multiple Cox regression analysis retained in the model only variables with p-values $\leq 0.05$. Regarding model selection, [19] suggested the consideration of issues such as clinical importance and adjustment for confounding, as well as statistical significance.

Let $0<t_{1}<t_{2}<t_{3}<\ldots<t_{k}<\infty$ be $\mathrm{k}$ observed times to the onset of CKD in HIV/AIDS patients during the observation period; $d_{i j}(i=1,2, \ldots, r ; j=1,2, \ldots, k)$ be the respective number of HIV/AIDS patients in the $\mathrm{i}^{\text {th }}$ group with CKD at each of these times; and $n_{i j}$ be the corresponding number of remaining patients in the cohort at the respective times. Then Kaplan-Meier (KM) estimate of the survivor function $S_{i}(t)(i=1,2, \ldots, r)$ when times to the onset of CKD in patients in the $\mathrm{i}^{\text {th }}$ group are tied is [20]. 


$$
\hat{S}_{i}(t)=\prod_{j \mid t_{j} \leq t} 1-\left(\frac{d_{i j}}{n_{i j}}\right), i=1,2, \ldots, r(3)
$$

In this study, the $r$ groups were the levels of the significant categorical covariates or categorized continuous covariates retained in the Cox regression analysis of CKD. The log-rank test was used to test the null hypothesis [20],

$H_{0}: S_{1}(t)=S_{2}(t)=\cdots=S_{r}(t) \equiv h_{1}(t)=h_{2}(t)=\cdots=h_{r}(t)(4)$

for $\mathrm{t} \geq 0$, where $h_{i}(t) \mathrm{s}$ the hazard function of the $\mathrm{i}^{\text {th }}$ group patients. Data for the study were recorded on research tools and then captured on Microsoft excel database and checked against original records by two competent individuals. Data were analysed using R Version 3.5.1.

\section{Results}

\section{Prevalence of CKD}

From the sample of $320 \mathrm{HIV/AIDS}$ patients: 51 patients (15.9\%) had CKD; $27(52.9 \%)$ of the 51 were males; $46(88.7 \%)$ of the 51 patients were from Embhuleni hospital. A follow-up of the patients with CKD gave rise to the following vital outcomes: $23.5 \%$ were lost to follow-up; $41.2 \%$ were transferred from the original hospitals and $35.3 \%$ remained attached at the hospitals. Out of 157 (49.1\%) HIV/ AIDS who transferred from the hospitals, $13.4 \%$ had CKD while from $84(26.3 \%)$ who were lost to follow-up, $14.3 \%$ had CKD.

\section{Cox model fit for risk factors associated with the onset of CKD}

The function ' $\operatorname{coxph}()$ ' in $\mathrm{R}$ fits a Cox proportional hazards regression model. Table 1 shows the results that were obtained from the fitted Cox regression model. A test for proportional hazards for each covariate in table 1 along with a global test for the model was done in $\mathrm{R}$ with the 'cox.zph()' function. The likelihood-ratio $(\mathrm{p}$-value $=0.0000)$, Wald $(\mathrm{p}$-value $=0.0000)$, and Score $(\log$-rank $)$ ( $\mathrm{p}$-value $=0.0000)$ statistics test the omnibus null hypothesis that all of the $\beta s$ are zero are all asymptotically equivalent and are in close agreement in soundly rejecting the omnibus null hypothesis. The model gives a high concordance of $81.6 \%$ which implies a high degree of discrimination between patients with and patients without CKD. There is no evidence of non-proportional hazards for all the covariates since the p-value $>0.05$ for each covariate in the model. The global chi-square test ( $\mathrm{p}$-value $=0.5486$ ) is non-significant, this implies that the assumption of proportionality is not violated. The good model fit statistics indicate that the model is ideal for all the variables (Table 1).

Table 1 which contains the results from Cox regression analysis of the data shows that the significant factors which are positively associated with CKD hazard at 0.05 level and have significant effects on $\mathrm{CKD}$ are: age ( $\mathrm{p}$-value $=0.0008)$, hospital (Embhuleni relative to Carolina) ( $p$-value $=0.0026)$ and baseline creatinine ( $p$-value $=0.0025)$. The description that follows for each covariate assumes that other covariates in the model are held constant. The estimated 95\% confidence interval of the hazard ratio for Age is $(1.0232,1.0908)$, which implies that every one-year increase in the age of an HIV/AIDS patient results in CKD hazard increase by a factor of 1.0565 or by about $5.7 \%$ and which is as much as $9.1 \%$ low to $2.3 \%$ lower. The estimated $95 \%$ confidence interval of the hazard ratio for baseline creatinine is $(1.0060,1.0286)$, which implies that for every one-unit increase in the baseline creatinine level of an HIV/AIDS patient, the CKD hazard rate is as much as $2.9 \%$ low to $0.6 \%$ lower. Furthermore, Embhuleni hospital has a hazard to CKD which is about 4.4 times the hazard of Carolina hospital to CKD and this hazard may be as high as 11.5 times and as low as 1.7 times.

On the other hand, the significant factors which are negatively associated with CKD hazard at 0.05 level are: gender (female relative to male) ( $\mathrm{p}$-value $=0.0356$ ), follow-up alanine transaminase (p-value $=0.0152), \quad$ Treatment $(\mathrm{EFV}+\mathrm{D} 4 \mathrm{~T}+3 \mathrm{TC}$ relative to $\mathrm{NVP}+\mathrm{D} 4 \mathrm{~T}+3 \mathrm{TC}) \quad(\mathrm{p}$-value $=0.0003), \quad$ Treatment $\quad(\mathrm{EFV}+\mathrm{AZT}+3 \mathrm{TC}$ relative to $\mathrm{NVP}+\mathrm{D} 4 \mathrm{~T}+3 \mathrm{TC})(\mathrm{p}$-value $=0.0019)$, Treatment $(\mathrm{EFV}+3 \mathrm{TC}+\mathrm{TDF}$ relative to $\mathrm{NVP}+\mathrm{D} 4 \mathrm{~T}+3 \mathrm{TC}) \quad(\mathrm{p}$-value $=0.0001)$ and Treatment $(\mathrm{NVP}+3 \mathrm{TC}+\mathrm{TDF}$ relative to $\mathrm{NVP}+\mathrm{D} 4 \mathrm{~T}+3 \mathrm{TC})$ ( $\mathrm{p}$-value $=0.0010)$. Explanations of the results which are negatively associated with CKD follow. The estimated 95\% confidence interval of the hazard ratio for gender is $(0.2747,0.9561)$, which implies female relative to male has a hazard reduction effect to CKD which is about 0.5 times and which is as much as $9.6 \%$ low to $2.7 \%$ lower. The estimated $95 \%$ confidence interval of the hazard ratio for followup alanine transaminase is $(0.9605,0.9957)$, which implies that an

Table 1: The estimates of the final Cox PH model.

\begin{tabular}{|l|c|c|c|c|c|c|c|}
\hline & coef & exp(coef) & se(coef) & $\mathbf{p}$ & Lower 0.95 CL & Upper 0.95 CL & rho chi sq p -value (PH test) \\
\hline Follow-up CD4 & -0.0009 & 0.9992 & 0.0011 & 0.4534 & 0.9187 & 0.9970 & 1.0014 \\
\hline Age & 0.0549 & 1.0565 & 0.0163 & 0.0008 & 1.0232 & 1.0908 & 0.8031 \\
\hline $\begin{array}{l}\text { EFV+D4T+3TC relative to } \\
\text { NVP+D4T+3TC }\end{array}$ & -1.9022 & 0.1493 & 0.5232 & 0.0003 & 0.0535 & 0.4161 & 0.5239 \\
\hline $\begin{array}{l}\text { EFV+AZT+3TC relative to } \\
\text { NVP+D4T+3TC }\end{array}$ & -2.6245 & 0.0725 & 0.8464 & 0.0019 & 0.0138 & 0.3808 & 0.6105 \\
\hline $\begin{array}{l}\text { EFV+3TC+TDF relative to } \\
\text { NVP+D4T+3TC }\end{array}$ & -2.0227 & 0.1323 & 0.5074 & 0.0001 & 0.0489 & 0.3577 & 0.2283 \\
\hline $\begin{array}{l}\text { NVP+3TC+TDF relative to } \\
\text { NVP+D4T+3TC }\end{array}$ & -1.9836 & 0.1376 & 0.6024 & 0.0010 & 0.0422 & 0.4481 & 0.6034 \\
\hline $\begin{array}{l}\text { Hospital (Embhuleni relative to } \\
\text { Carolina) }\end{array}$ & 1.4778 & 4.3835 & 0.49039 & 0.00258 & 1.6765 & 11.4614 & 0.2136 \\
\hline Follow-up alanine transaminase & -0.0223 & 0.9779 & 0.0092 & 0.0152 & 0.9605 & 0.9957 & 0.0754 \\
\hline Ln Follow-up viral load & 0.0640 & 1.0661 & 0.0587 & 0.27541 & 0.9503 & 1.1961 & 0.8447 \\
\hline Baseline creatinine & 0.0171 & 1.0172 & 0.0057 & 0.0025 & 1.0060 & 1.0286 & 0.3802 \\
\hline Follow-up lymphocyte & 0.0320 & 1.0325 & 0.0301 & 0.2886 & 0.9733 & 1.0952 & 0.7279 \\
\hline Gender (female relative to male) & -0.6684 & 0.5125 & 0.3181 & 0.0356 & 0.2747 & 0.9561 & 0.4277 \\
\hline
\end{tabular}


increase in follow-up alanine transaminase by one unit results in a hazard reduction effect to CKD by a factor of 0.9780 or by about $2.2 \%$ and which is as much as $4.1 \%$ low to $0.4 \%$ lower. Patients taking Treatments $(\mathrm{EFV}+\mathrm{D} 4 \mathrm{~T}+3 \mathrm{TC}, \mathrm{EFV}+\mathrm{AZT}+3 \mathrm{TC}, \mathrm{EFV}+3 \mathrm{TC}+\mathrm{TDF}$, or $\mathrm{NVP}+3 \mathrm{TC}+\mathrm{TDF}$ each relative to $\mathrm{EFV}+3 \mathrm{TC}+\mathrm{TDF}$ ) are likely to experience $\mathrm{CKD}$ hazard reduction by about 0.15 times, 0.07 times, 0.13 times, or 0.14 times respectively.

\section{Nonparametric inferences about the survivor functions}

The cohort of HIV+ terminal patients in this study is not homogeneous with respect to their characteristics that may affect their survival from CKD. Hence, it will be necessary to test the equality of survivor functions among groups (strata) of patients. The function 'survdiff()' was used to test for the differences in survival between two groups using a log-rank test. Log-rank tests and the Kaplan-Meier functions presented in this section are for gender, age and creatinine. These variables constitute Glomerular Filtration Rate (GFR) equation given by Omuse G, et al., [15]. Treatment (regimen one) is also included in this section because of its clinical significance among HIV/ AIDS patients.

Baseline creatinine was categorised as done in the standard Laboratory report on creatinine in South African hospitals. Figure 1 shows that survivor functions of the baseline creatinine strata are statistically different at 0.05 significance level ( $\mathrm{p}$-value $=0.004$, from the log-rank test) and this confirms that baseline creatinine level is associated with CKD hazard. This is further confirmed by the pair-wise comparisons of the strata using the hazard ratios in table 2 which show that patients with baseline creatinine level which is above normal level are about 2.5 times likely to experience CKD relative to patients with baseline creatinine which is at a normal level. This risk can be as low as about 1.3 times and as high as about 4.7 times (Table 2). The difference in CKD experience between patients with baseline creatinine level below normal relative to patients with baseline creatinine at a normal level is statistically not significant (Table 2).

Table 2 shows that female patients relative to male patients have a reduced risk of CKD of about 0.6 times. However, the effect of gender is statistically not significant in the experience of CKD hazard. This is confirmed by the survivor functions of gender strata which are not statistically different at 0.05 significance level ( $p$-value $=0.05$, from the log-rank test) (Figure 2) and also by the confidence limits for gender strata in table 2 which include ' 1 ' which is a value of no effect.

Figure 3 shows that survivor functions of the age strata are not statistically different at 0.05 significance level ( $p$-value $=0.08$, from the log-rank test) and this is confirmed by the confidence limits for strata in table 2 which include ' 1 ' which is a value of no effect. Patients who are above 50 years relative to patients aged 16-30 years are about 2.7 times likely to experience CKD (Table 2). Patients aged 31-50 years relative to patients aged $16-30$ years are about 1.5 times likely to experience CKD. However, this difference is not significant since the 95\% confidence limits include 1 (a result of no effect) and also the graphs of 31-50 and 16-30 age groups cross each other as shown in figure 3.

The five treatment groups are statistically different (log-rank $\mathrm{p}$-value $=0.003) \quad$ (Figure 4). Treatment $\mathrm{EFV}+\mathrm{D} 4 \mathrm{~T}+3 \mathrm{TC}$ relative to treatment $\mathrm{NVP}+\mathrm{D} 4 \mathrm{~T}+3 \mathrm{TC}$ has reduced risk to $\mathrm{CKD}$ of about 0.34 times, Treatment EFV $+\mathrm{AZT}+3 \mathrm{TC}$ relative to treatment $\mathrm{NVP}+\mathrm{D} 4 \mathrm{~T}+3 \mathrm{TC}$ has reduced risk to $\mathrm{CKD}$ of about 0.1 times while treatment $\mathrm{EFV}+3 \mathrm{TC}+\mathrm{TDF}$ relative to $\mathrm{NVP}+\mathrm{D} 4 \mathrm{~T}+3 \mathrm{TC}$ has reduced risk to $\mathrm{CKD}$ of about 0.4 times. The effect of treatment NVP+3TC+TDF relative to $\mathrm{NVP}+\mathrm{D} 4 \mathrm{~T}+3 \mathrm{TC}$ is not statistically significant in experiencing the risk of CKD since the graphs cross (Figure 4 ) and the $95 \%$ confidence internal includes a value of no effect ' 1 ' (Table 2).

\section{Discussion}

This research has several strengths. Firstly, the research followup time of 7.5 years is relatively long to yield consistent records and hence reliable findings. Secondly, the research has diverse covariates with most of them having paired baseline and follow-up covariates for exhaustive comparisons of associations. Finally, this was not a singlecenter study; it involved two district hospitals namely Embhuleni and Carolina for comparison and completeness in coverage.

The researched prevalence of CKD among HIV/AIDS patients in Albert Luthuli municipality of South Africa was $15.9 \%$. This prevalence is within the range of $6 \%$ to $45 \%$ which is the CKD prevalence in HIV patients in Africa as cited by Moosa MR, et al., [21]. Similar studies which were carried out in South Africa for example by Zachor $\mathrm{H}$, et al., [22] in Cape Town and by Moosa MR, et al., [21] in South Africa showed the prevalence of $2 \%-6 \%$. The difference between the prevalence findings could be explained by study design, population variation, variables considered and the criteria used for the diagnosis of CKD. The prevalence of CKD among the lost and transferred patients in this research was $14.3 \%$ and $13.4 \%$ respectively. The patients lost to follow-up and the patients who transferred from the hospital were presumed to be part of the research and to be alive until the end of the research $[23,24]$.

The researched risk factors found to be associated with CKD by using Cox regression were gender, age, baseline creatinine, hospital, treatment (regimen 1) and baseline alanine transaminase. The finding in this research on risk factors to CKD concurs with the study findings by Kalayjian RC, et al., [24], Menezes AM, et al., [25], Nishijima T, et

Table 2: Hazard ratios for variables.

\begin{tabular}{|l|l|c|c|c|}
\hline \multicolumn{1}{|c|}{ Variable } & \multicolumn{1}{c|}{ Description } & Point Estimate & \multicolumn{2}{c|}{ 95\% Wald Confidence Limits } \\
\hline \multirow{3}{*}{ Baseline creatinine } & Below normal level relative to normal level & 0.5947 & 0.2095 & 1.688 \\
\cline { 2 - 5 } & Above normal relative to normal level & 2.4897 & 1.3233 & 4.684 \\
\hline \multirow{2}{*}{ Gender } & Female relative to Male & 0.6183 & 0.3561 & 1.073 \\
\hline \multirow{2}{*}{ Age groups } & 31-50 years relative to 16-30 years & 1.468 & 0.7748 & 2.782 \\
\cline { 2 - 5 } & Above 50 years relative to 16-30 years & 2.660 & 1.1070 & 6.393 \\
\hline \multirow{3}{*}{ ART regimen strata } & EFV+D4T+3TC relative to NVP+D4T+3TC & 0.3443 & 0.1354 & 0.8759 \\
\cline { 2 - 5 } & EFV+AZT+3TC relative to NVP+D4T+3TC & 0.1045 & 0.0221 & 0.4957 \\
\cline { 2 - 5 } & EFV+3TC+TDF relative to NVP+D4T+3TC & 0.4019 & 0.1779 & 0.9079 \\
\cline { 2 - 5 } & NVP+3TC+TDF relative to NVP+D4T+3TC & 0.3973 & 0.1550 & 1.0186 \\
\hline
\end{tabular}




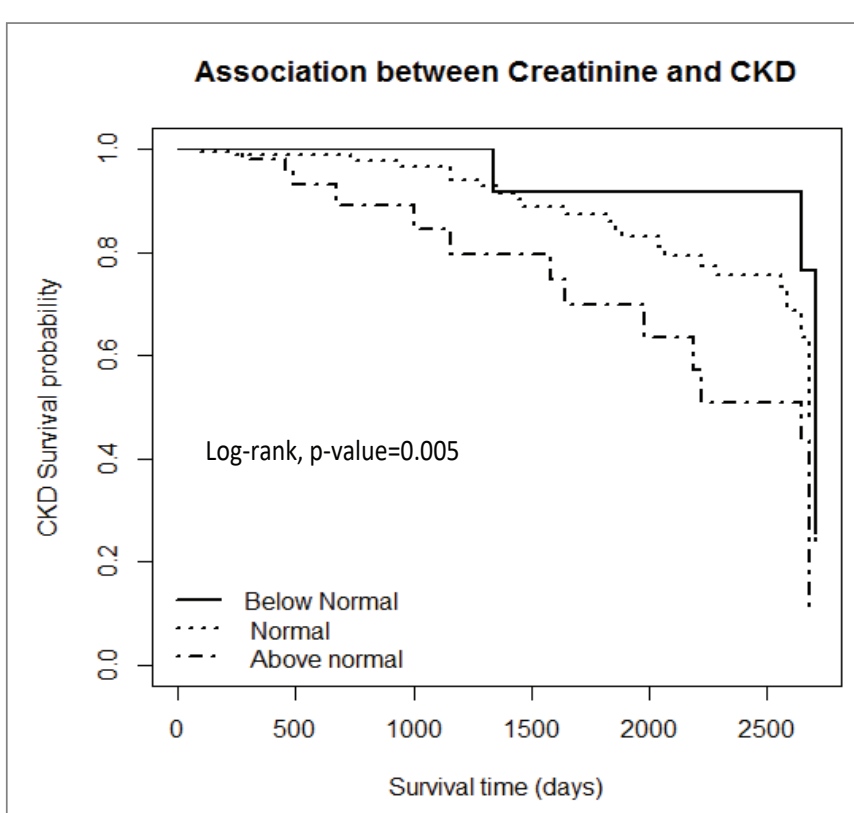

Figure 1: Kaplan-Meier survival function estimates for Baseline creatinine strata.

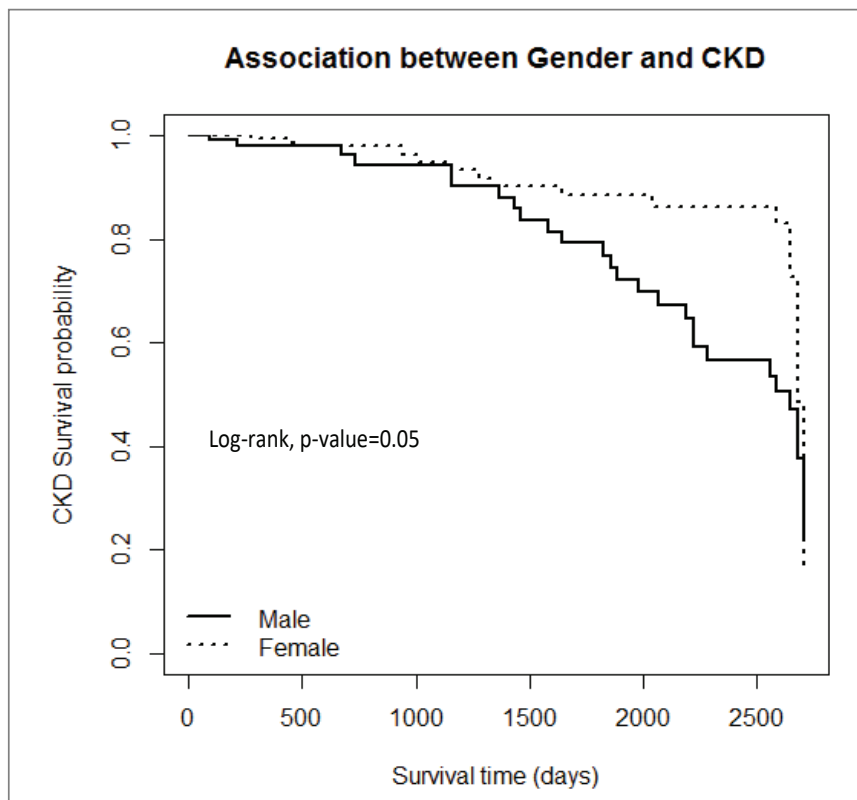

Figure 2: Kaplan-Meier survival function estimates for Gender.

al., [26], Hilton R [27], Boswell MT, et al., [28], and Crum-Cianflone N, et al., [10] who had HIV, race, sex, age, low CD4, high viral load, diabetes, ART, weight, high sodium and hypertension as the risk factors to kidney disease. However, there is no consensus among researchers on the effect of TDF-containing ART regimens on CKD. Although ART may improve kidney function, TDF-containing regimens have been found to have the potential to cause nephrotoxicity and hence to significantly contribute to CKD among HIV-infected patients. This finding agrees with studies by Boswell MT, et al., [28], Wyatt CM, et al., [29], and Kalayjian RC, et al., [24], pointed out that TDF is associated with kidney toxicity and a decrease in creatinine

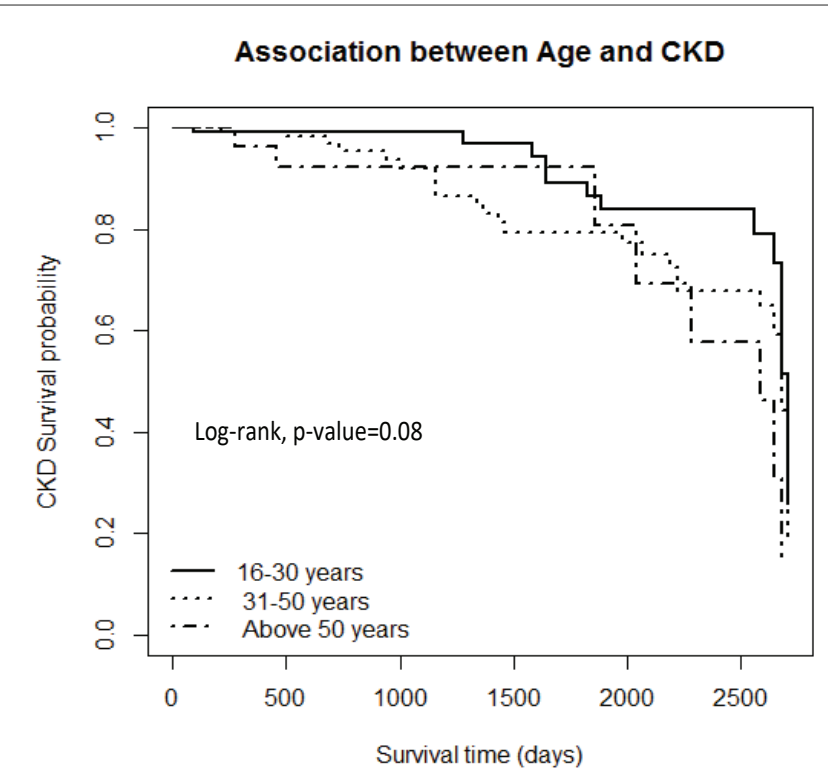

Figure 3: Kaplan-Meier survival function estimates for Age groups.

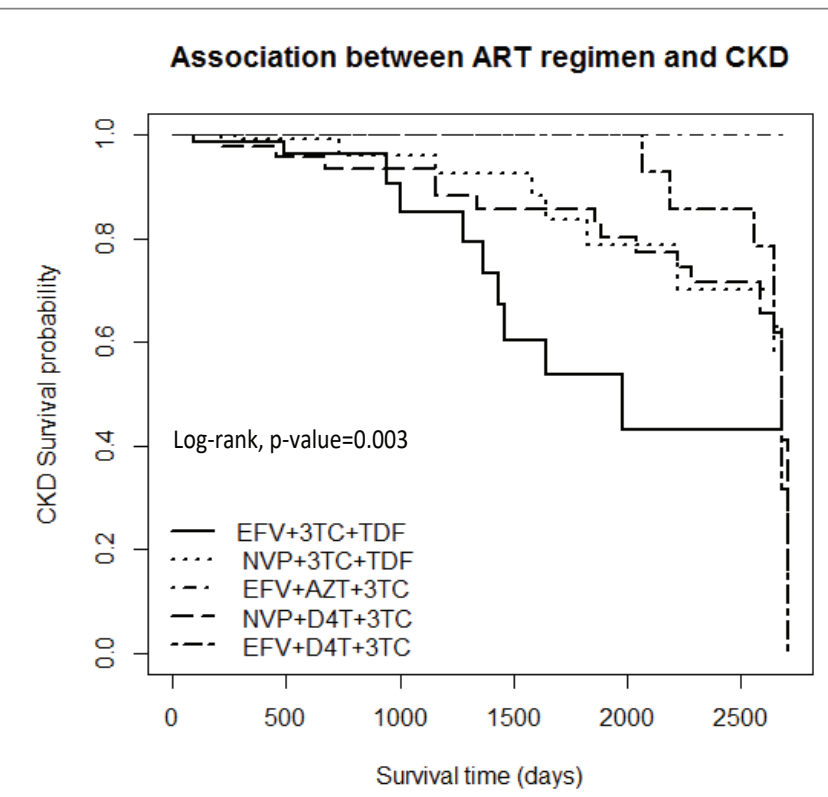

Figure 4: Kaplan-Meier survival function estimates for ART regimen strata.

clearance or decrease in GFR. In this study, treatment (regimen 1) is negatively associated with CKD hazard, in both univariate and multiple Cox regression forms. Unexpectedly, in this study, TDF-containing regimens which happen to have a greater number of CKD cases $(60.8 \%)$ in comparison to other regimens have a negative association with CKD hazard relative to NVP+D4T+3TC (reference regimen). Thus, despite most CKD cases being found among patients taking TDF-containing drugs, TDF-containing drugs are still associated with a CKD hazard reduction effect. Some further studies on the association between TDF-containing drugs and CKD hazard in necessary. 
The baseline findings from figure 1 and table 2 show that patients with baseline creatinine which is above normal level are about 2.5 times likely to experience CKD relative to patients with baseline creatinine which is at a normal level. In addition, patients with baseline creatinine which is below normal level are about 0.6 times likely to experience CKD relative to patients with baseline creatinine which is at a normal level. These findings reinforce the need for accuracy in creatinine testing and the inclusion of creatinine in the GFR equation.

Gender is significant in modeling (Table 1) but not significant in the testing of the hypothesis of no difference of homogeneity using the Log-rank test and Kaplan-Meier functions (Figure 2, Table 3). This difference is because Cox modeling accounts for the effects of other factors whereas Kaplan-Meier is a univariate analysis that does not consider the effects of other variables. A research study in Albert Luthuli found out that being male increases the hazard of having CKD by about 1.6 times. The significance of gender as a risk factor to CKD is reinforced by its inclusion in the MDRD formula.

Another significant researched risk factor to $\mathrm{CKD}$ and which happens to be included in the GFR formula is age. The fitting of age in the Cox regression in this study reinforces its inclusion in the GFR formula. The effect of age on CKD is due to the glomerular filtration rate which declines at $6.3 \mathrm{ml} / \mathrm{min} / 1.73 \mathrm{~m}^{2}$ per decade as cited by Denic A, et al., [30]. Findings on age in table 4 indicate that patients aged above 50 years relative to patients aged 16-30 years are about 2.7 times likely to experience CKD.

The finding that CKD is associated with baseline creatinine, age and gender are not novel as these are the components of the GFR formula $[14,15]$. Therefore, the concurrence of the regression results with the existing formula in the background of around 30 independent factors confirms the appropriateness and accuracy of the research methods used.

On the management of CKD; Pedro C, et.al., [31] supported the use of TDF but hinted at its nephrotoxic potential and pointed out the need for the adjustment of the dose when baseline creatinine clearance is below $50 \mathrm{ml} / \mathrm{min}$. Boswell MT, et al., [28], pointed out that current local guidelines recommend that TDF be substituted by an alternative Nucleoside Reverse Transcriptase Inhibitors (NRTI) when a patient's GFR is less than $50 \mathrm{ml} / \mathrm{min}$ and when using the MDRD method [21] gave some guidelines on dose adjustments for ART in CKD cases for Lamivudine (3TC), Stavudine (d4T) and Tenofovir (TDF). Some other points to note on the management of CKD as cited by several studies are:

- All individuals should be assessed for kidney disease at the time of diagnosis of HIV/AIDS and annually thereafter.

- Prevention of CKD at the population level through interventions that lead to a reduction in BP, obesity, type 2 diabetes mellitus, smoking and salt ingestion.

- Careful screening and monitoring of high-risk patients.

- Increased awareness of CKD and knowledge on how to manage kidney disease should be emphasized for general medical practitioners.

Labuschagne I, et al., [7] cited main challenges in the handling of CKD; firstly, the extent of the HIV epidemic and its associated burden on $\mathrm{CKD}$, secondly there are no measures to prevent renal disease in people living with HIV or to detect CKD early enough to treat it and lastly the challenge of a rise in diet-related non-communicable diseases such as obesity and hypertension. Some other challenges include costly dialysis; in 2017 South Africa had only three public hospitals which offered kidney transplants.

The researcher acknowledges several limitations in this study. First, despite hypertension and diabetes being regarded by many studies as important risk factors to $\mathrm{CKD}$, they could not be included because of missing data. However, the contribution of hypertension and diabetes to the development of CKD was not significant in similar studies [5]. Second, this research had predominantly black participants and hence it failed to evaluate the effect of race on CKD as was done by Winston J, et al., [32] and Hilton R [27], who showed that the black race is the most important determinant of kidney disease prevalence in HIVinfected persons. Lastly, Bukabau JB, et al., [33] in agreement with Ekrikpo UE, et al., [8] proposes that the MDRD which was used in this study as a creatinine-based formula is inadequate for the African population.

\section{Conclusion}

The research findings on HIV/AIDS patients in Albert Luthuli Municipality concurred with several previous research findings on factors associated with CKD. The prevalence of CKD among HIV/AIDS patients in Albert Luthuli Municipality was found to be $15.9 \%$. The application of Cox regression found the factors associated with CKD as gender, age, baseline creatinine, hospital, treatment (regimen 1) and Baseline alanine transaminase. The study established diverse baseline statistics against which future research may be based.

\section{Acknowledgment}

We are grateful to HIV/AIDS clinic staff for Carolina and Embhuleni hospitals. The Data capturers assisted with data collection while the administrative staff swiftly performed data collection permissions protocols.

\section{Authors' Information}

\section{Author notes}

Pepukai Bengura, Principal Ndlovu and MulaloAnnah Managa contributed equally to this work hence the corresponding author is transferable if the need arises.

\section{Authors' contributions}

PB was involved in obtaining ethics approval, data collection/ analysis and drafting of the manuscript. PD and MAM contributed to data interpretation, project design and editing the manuscript. All authors read and approved the final manuscript.

\section{Funding}

None.

\section{Ethics Declarations}

\section{Ethics approval and consent to participate}

This study was conducted in accordance with the South African local and national research guidelines. Ethics approval for this project was obtained from UNISA Ethics Review Committee (ERC) with the approval number being (2017/SSR ERC/005). The permission to conduct the study at Carolina and Embhuleni hospitals was obtained from Mpumalanga Department of Health with the permission number being (MP_201708_013). The consent to participate does not apply to a patient since no reference to an individual respondent was made; all results were handled in aggregate format. 


\section{Availability of Data and Materials}

The data that support the findings of this study are available from the Department of health, but restrictions apply to the availability of these data, which were used under license for the current study, and so are not publicly available. Data are however available from the authors upon reasonable request and with permission of the Department of health.

\section{Consent for Publication}

Not applicable.

\section{Competing Interests}

The authors declare that they have no competing interests.

\section{References}

1. World Health Organization (2018) The Global Health Observatory (GHO). Geneva, Switzerland.

2. United Nations Programme on HIV/AIDS (UNAIDS) (2019) People Living With HIV Receiving Art (\#) (As of 30 June). Geneva, Switzerland.

3. Motsoaledi A (2013) Mpumalanga's Gert Sibande district has highest HIV rate. Johannesburg, Johannesburg, South Africa.

4. Nkosi PA (2017) Chief Albert Luthuli local municipality Integrated Development Plan (IDP) 2017-2022.

5. Mekuria Y, Yilma D, Mekonnen Z, Kassa T, Gedefaw L (2016) Renal Function Impairment and Associated Factors among HAART Naïve and Experienced Adult HIV Positive Individuals in Southwest Ethiopia: A Comparative Cross Sectional Study. PLoS One 11: e0161180.

6. Glaser N, Phiri S, Bruckner T, Nsona D, Tweya H, et al. (2016) The prevalence of renal impairment in individuals seeking HIV testing in Urban Malawi. BMC Nephrol 17: 186.

7. Labuschagne I, Nel J (2017) Chronic kidney disease is still a major health challenge in Africa.

8. Ekrikpo UE, Kengne AP, Bello AK, Effa EE, Noubiap JJ, et al. (2018) Chronic kidney disease in the global adult HIV-infected population. A systematic review and meta-analysis. PLoS One 13: e0195443.

9. Eneyew K, Seifu D, Amogne W, Menon MKC (2016) Assessment of Renal Function among HIV-Infected Patients on Combination Antiretroviral Therapy at Tikur Anbessa Specialized Hospital, Addis Ababa, Ethiopia. Sci Res Pub 7: 107-122.

10. Crum-Cianflone N, Ganesan A, Teneza-Mora N, Riddle M, Medina $S$, et al. (2010) Prevalence and factors associated with renal dysfunction among HIV-infected patients. AIDS Patient Care STDS 24: 353-360

11. Stanifer JW, Jing B, Tolan S, Helmke N, Mukerjee R, et al. (2014) The epidemiology of chronic kidney disease in sub-Saharan Africa: a systematic review and meta-analysis. Lancet Glob Health 2: e174-e181.

12. Kaze AD, Ilori T, Jaar BG, Echouffo-Tcheugui JB (2018) Burden of chronic kidney disease on the African continent: a systematic review and meta-analysis. BMC Nephrol 19: 125.

13. Damtew B, Mengistie B, Alemayehu T (2015) Survival and determinants of mortality in adult HIV/Aids patients initiating antiretroviral therapy in Somali Region, Eastern Ethiopia. P Pan Afr Med J 22: 138.

14. Iseki K (2010) Renal outcomes in chronic kidney disease. Nephrology (Carlton) 15: 27-30.
15. Omuse G, Maina D, Mwangi J, Wambua C, Kanyua A, et al. (2017) Comparison of equations for estimating glomerular filtration rate in screening for chronic kidney disease in asymptomatic black Africans : a cross sectional study. BMC Nephrol 18: 369.

16. Klein JP, Moeschberger ML (2003) Survival Analysis. In: Dietz K, Krickeberg K, Gail M, Singer B (eds) Techniques for Censored and Truncated Data. Springer, USA.

17. Etikan I, Babatope G (2018) Survival Analysis: A Major Decision Technique in Healthcare Practices. Int J Sci Res Methodol 8: 121-135.

18. Kleinbaum DG, Klein M (2012) Survival Analysis. A Self-Learning Text. Springer, USA.

19. Hosmer DW, Lemeshow S, May S (2008) Applied Survival Analysis: Regression Modeling of Time to Event Data. $2^{\text {nd }}$ edition, John Wiley and Sons Inc, New York.

20. Etikan I, Abubakar S, Alkassim R (2015) The Kaplan Meier Estimate in Survival Analysis. Biom Biostat Int J 5: 55-59.

21. Moosa MR, der Walt VI, Naicker S, Meyers AM (2015) Important causes of chronic kidney disease in South Africa. S Afr Med J 105: 1-8.

22. Zachor H, Machekano R, Estrella MM, Veldkamp PJ, Zeier MD, et al. (2016) Incidence of stage 3 chronic kidney disease and progression on tenofovir-based regimens. AIDS 30: 1221-1228.

23. Goel MK, Khanna P, Kishore J (2010) Understanding survival analysis: Kaplan-Meier estimate. Int J Ayurveda Res 1: 274-278.

24. Kalayjian RC, Lau B, Mechekano RN, Crane HM, Rodriguez B, et al. (2012) Risk factors for chronic kidney disease in a large cohort of HIV-1 infected individuals initiating antiretroviral therapy in routine care. AIDS 26: 1907-1915.

25. Menezes AM, Torelly Jr J, Real L, Bay M, Poeta J, et al. (2011) Prevalence and risk factors associated to chronic kidney disease in HIV-infected patients on HAART and undetectable viral load in Brazil. PLoS One 6: e26042.

26. Nishijima T, Kawasaki Y, Mutoh Y, Tomonari K, Tsukada K, et al. (2017) Prevalence and factors associated with chronic kidney disease and end-stage renal disease in HIV-1-infected Asian patients in Tokyo. Sci Rep 7: 14565.

27. Hilton $R$ (2013) Human immunodeficiency virus infection and kidney disease. J R Coll Physicians Edinb 43: 236-239.

28. Boswell MT, Rossouw TM (2017) Approach to acute kidney injury in HIV-infected patients in South Africa. South Afr J HIV Med 18: 714.

29. Wyatt CM (2017) Kidney Disease and HIV Infection. Top Antivir Med 25: 13-16.

30. Denic A, Glassock RJ, Rule AD (2016) Structural and Functional Changes with the Aging Kidney. Adv Chronic Kidney Dis 23: 19-28.

31. Pedro C, Alberto O, Karina S (2016) HIV and kidney diseases: 35 years of history and consequences. Clin Kidney J 9: 772-781.

32. Winston J, Deray G, Hawkins T, Szczech L, Wyatt C, et al. (2008) Kidney Disease in Patients with HIV Infection and AIDS. Clin Infect Dis 47: 1449-1457.

33. Bukabau JB, Yayo E, Gnionsahe A, Monnet D, Pottel H, et al. (2019) Performance of creatinine-or cystatin C-based equations to estimate glomerular filtration rate in sub-Saharan African populations. Kidney Int 95: 1181-1189. 